\title{
Carotid Graft Replacement of the Stenotic Carotid Artery
}

\author{
Igor Koncar, Nikola llic, Marko Dragas, Igor Banzic, Miroslav Markovic, \\ Dusan Kostic and Lazar Davidovic
}

Additional information is available at the end of the chapter

http://dx.doi.org/10.5772/54028

\section{Introduction}

It is well known connection between the stroke and diseases of carotid artery (stenosis, aneurysm, kinking). In the XIX century postmortem studies showed association of ischemic brain lesions and plaque formation in carotid bifurcation [1]. Later in 1937 Egaz Moniz performed first angiography while neurologists started to consider connection between carotid and brain lesions, and very soon idea for surgical treatment was born [2]. In 1951, in Buenos Aires, Carrea performed external to internal carotid artery bypass, and published it in 1955 [3]. In the period from 1955-1975 different important cardiovascular surgical groups published their reports about surgical treatment of carotid stenosis in symptomatic patient using different reconstructive procedures. Eastcot, Pickering and Rob in 1954 reported resection of carotid bifurcation and internal to common carotid artery bypass, while DeBakey, then Row and Cooley performed carotid endarterectomy (CEA) - plaque removal instead of bypass $[4,5,6,7]$. Afterwards idea of plaque removal instead of bypass was accepted widely, and its' efficacy in stroke prevention was later proved in multiple trials [8, $9,10,11,12,13]$.

Still, diverse pathologies of carotid artery were treated even before this obsession with carotid stenosis. French surgeon LeFevre used external carotid artery for flow restoration in case of traumatic lesion of internal carotid artery [14]. In the golden fifties, when carotid surgery was born, other authors reported their experience in treatment of carotid aneurysms $[15,16]$. Although Dimitza used resection and reanastomosis, Beall had to use graft interposition. In this position authors were using autologous and synthetic graft with similar results; however in region susceptible to infection, autologous graft was preferred. DeBakey also reported his results in usage of graft replacement in case of carotid trauma [17]. In the beginning of treatment of carotid stenosis there were also reports of different 
techniques similar to those described in trauma and aneurysmatic disease. Dehnman et al treated carotid occlusion with homograft while Doyle et al used saphenous vein for treatment of carotid stenosis $[18,19]$

On the other side, endarterectomy as surgical method for the treatment of stenotic arterial lesions was performed on superficial femoral artery, by Dos Santos, and later with extensive usage of Heparin it gain more success and showed its role in aorto-iliac position [20, 21]. Further experience showed its' excellent effect in focal stenotic lesions in vessels with largecaliber and high-flow rate. In everyday clinical practice this technique has proved efficient in patients with localized disease limited to the distal aorta or proximal iliac arteries and distal common femoral artery obstructing deep femoral artery orifice (profundoplasty) [22, $23,24]$. On the contrary in extensive atherosclerotic pattern that are more frequent in clinical practice, endarterectomy is technically demanding with poor long term results [25]. Later trough history, short lesions were preferably treated by endovascular means, leaving bypass reconstruction for longer ones, while isolated endarterectomy is becoming almost forgotten except in carotid bifurcation. It is rarely recognized in the literature that in some, not frequent, situations endarterectomy in stenotic carotid artery is not possible or it might be jeopardized. What are modes of reconstruction of carotid artery when CEA fails or is not possible? If bypass or graft replacement is alternative in peripheral occlusive disease, should we apply it in carotid position as well in situations when extensive disease is encountered or technical challenge happens?

\section{Aim of the chapter}

The aim of this chapter is to show results and experience of a single high volume center in usage of synthetic graft in the treatment of extensive carotid atherosclerotic disease and to analyze published results related to this topic.

\section{Material and methods}

Clinic for Vascular and Endovascular Surgery of the Serbian Clinical Center is located in Belgrade, Serbia, and it was part of the Second surgical clinic, the cradle of cardiovascular medicine in the former Yugoslavia. First vascular procedures were performed in its' facilities in the sixties (1966) by outstanding pioneers of this, in that time, new branch of surgery - V. Stojanovic and B. Vujadinovic. Figure 1 (A and B). Further development of this institution was supported by the fact that it becomes educational and referral center. Intensive cooperation with leading world centers of excellence, sending its practitioners for education and organizing demonstrational operations in own facilities contributed to popularization and development of cardiovascular surgery in the former Yugoslavia, Balkans and Eastern Europe with consequent progress in treatment of cardiovascular patients in this institution. Later S.Lotina, (Figure 1 - C) successor of Stojanovic and Vujadinovic, has significant role in development of vascular surgery in this institution, since he struggled for segmentation of cardiovascular surgery in the late eighties and middle nineties and eventually achieved expansion of independent vascular department with 
surgeons and angiologists dedicated to this field. Later, Lazar Davidovic, (Figure 1 - D) one of his pupils, becomes new leader of this department accomplished to improve it to the level of the clinic. After finishing his education with fellowship at Pitié-Salpêtrière hospital in Paris, under the service of Prof Eduard Kieffer, where he improved his experience in aortic and carotid surgery, adopting eversion technique, L. Davidovic brought new modern perspectives in the diagnosis and treatment of vascular patients not only in this institution but rather in the whole country of Serbia. Since then the number of carotid and aortic procedures is annually increasing in this institution reaching almost 600 carotid and almost 500 aortic in the year 2011, with sensible and gradually introduction of endovascular procedures (carotid, peripheral stenting and endovascular repair of aortic pathology) according to published results, guidelines recommendation and available financial support of national health care system.

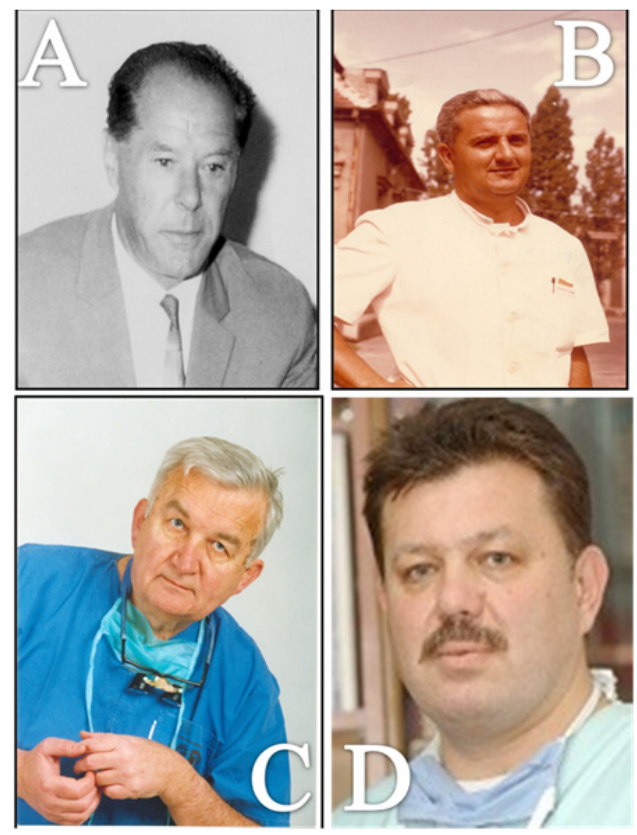

Figure 1. Leaders of development of vascular surgery in Serbian Clinical Centre in last 60 years. A. Vojislav Stojanovic (1955-1971) B. Borislav Vujadinovic (1971-1985) C. Slobodan Lotina (1985-2002) D. Lazar Davidovic (2002- still leading Clinic for Vascular and Endovascular Surgery)

In the period from January 2003 to October 2006, at the Clinic for Vascular and Endovascular Surgery of the Serbian Clinical Centre, 1250 procedures due to carotid artery stenosis in 1127 patients were performed. Carotid stenosis was repaired by eversion or conventional endarterectomy (CEA) and synthetic graft (Dacron $\left.{ }^{\circledR}\right)$ interposition in 987 (78, $96 \%), 205(16,4 \%)$ and $58(4,64 \%)$ patients respectively. We retrospectively analyzed prospectively gathered data related to the subgroup of patients operated with graft replacement. 
Indications for conventional EA with usage of protective intraluminal shunt were contralateral occlusion, recent stroke or transitory ischemic attack and intraoperative stump pressure below $40 \mathrm{mmHg}$. These patients were excluded from this analysis. Other patients were operated with eversion technique. Eversion EA was performed in the same manner as described elsewhere in the literature [26].

Indications for graft replacement (GR) were: extensive atherosclerotic disease proximal and/or distal to carotid bifurcation revealed intraoperatively during dissection or preoperatively by means of ultrasound, digital subtraction angiography (Figure 3.) or multidetector computed tomography; long segment of thrombotic surface after EA; bad quality of arterial wall after EA; inadequate end of the endarterectomy cleavage; any other technical problem that could endanger the success of procedure. Decision for GR was made by operating surgeon.

GR was performed after complete resection of carotid bifurcation and its removal. Dacron graft of 6 or $8 \mathrm{~mm}$ in diameter was used depending on the ICA and CCA diameter. Initially anastomosis between the graft and ICA was made, in the continuous fashion, "parachute" technique, with Prolene 6-0 suture. Upon finishing the anastomosis clamp was removed proximaly on the synthetic graft in order to verify anastomotic compatibility. Afterwards proximal anastomosis between CCA and synthetic graft was sutured with Prolene 5-0 in the same fashion. Flushing and air removal is of outmost importance before declamping since there is in-line flow directly to endocranial vascular bed without any patent branch. Reattachment of ECA was performed selectively according to its quality, position and already spent time for GR (Figure 2 and 3.).
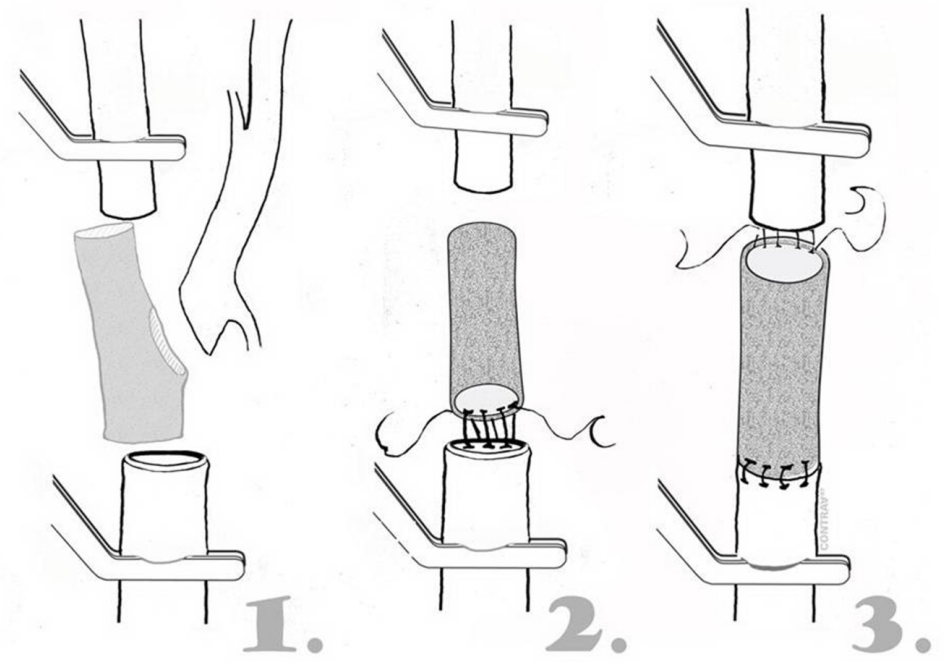

Figure 2. Schematic presentation of carotid graft replacement. A. Resection of carotid bifurcation B. Suturing distal anastomosis C. Suturing proximal anastomosis 


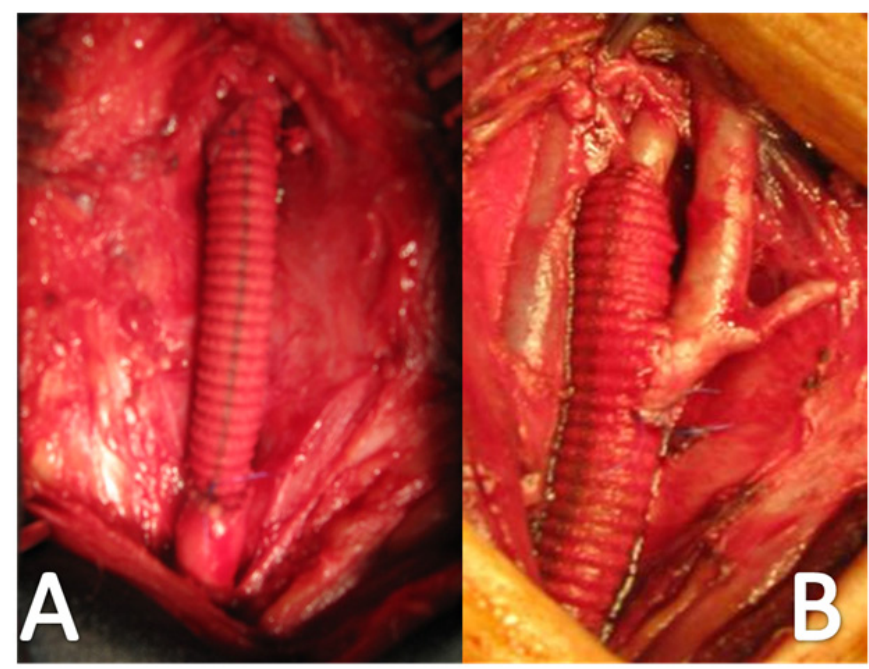

Figure 3. Intraoperative image of final graft reconstruction A. Dacron graft interposition B. Dacron graft interposition with reimplanted external carotid artery

In this period of time (2003-2006) cervical plexus block was introduced for carotid surgery in our institution, and consequently we changed the indications for conventional endarterectomy and shunt usage performing it only in case of neurological deterioration of the patient during carotid cross clamping. However patients treated with conventional EA with extensive atherosclerotic disease were not analyzed in this paper and GR was performed without usage of the intraluminal shunt.

Among 1045 procedures performed in 956 patients there were 987 (94, 45\%) treated with eversion EA and $58(5,55 \%)$ with GR. After excluding patients treated with conventional and eversion EA, we retrospectively analyzed preoperative, intraoperative and postoperative data of the patients treated with GR in order to investigate results of this alternative procedure and to try to define optimal indications for its' usage. After analyzing initial results deeper investigation was performed by dividing group of patients treated with GR in two groups according to the indication and decision to perform GR:

Group A, when decision to perform GR was made according to the ultrasonography exam and intraoperative findings before any attempted EA;

Group B when GR was made after failed EA as a bailout procedure.

In the preoperative data we analyzed age, sex, co-morbid conditions and preoperative ultrasound descriptions. All patients were preoperatively examined by ultrasonography means, describing quality and length of the plaque. All exams were made by experienced ultrasonographer. The quality of plaque was described as lipid, fibrous or calcified with or without present ulceration. The length of the plaque was defined as the longitudinal extent of the plaque narrowing arterial lumen for $30 \%$ and more. Plaques longer than $4 \mathrm{~cm}$ were named as long. 
After removing atherosclerotic plaque from internal carotid artery (ICA) and common carotid artery (CCA) its' quality (morphology) and length were assessed too. From intraoperative data we used the intraoperative length of atherosclerotic disease, reasons to perform GR (before any attempt to perform eversion or after attempted eversion), cross clamping time and restoration of external carotid artery flow.

Postoperative data were related to the neurological outcome and mortality rate as well as early surgical (hemorrhage, cranial nerve lesions, and wound infection) and cardiac complications. All patients were followed for one month and yearly thereafter with clinical and ultrasound examination.

\section{Results}

Among treated patients significant number was symptomatic - 30 (51, $72 \%)$ patients with previous transitory ischemic attack $(12-40 \%)$, ocular symptoms $(2-6,66 \%)$ or stroke (16$53,33 \%)$. Demographic characteristics of the patients and symptoms distribution were presented in the Table 1. There was no significant difference in terms of co-morbid conditions between the groups.

$\begin{array}{ccc}\text { Characteristic/ Group } & \text { Graft replacement } & \text { Subgroup A/B } \\ \text { Number of patients } & \mathrm{N}(\%) & \mathrm{N}(\%) \\ \text { Age } & \mathbf{5 8}(100) & \mathbf{4 0}(68.96) / \mathbf{1 8}(31.04) \\ \text { Male } & \mathbf{6 5 . 5 5} & \mathbf{6 6 . 8} / \mathbf{6 4 . 3} \\ \text { Arterial Hypertension } & \mathbf{5 0}(86.2) & \mathbf{3 4}(85) / \mathbf{1 6}(88.88) \\ \text { Smoking } & \mathbf{4 8}(82.75) & \mathbf{3 5}(87.5) / \mathbf{1 3}(72.22) \\ \text { Obesity } & \mathbf{4 0}(68.96) & \mathbf{2 8}(70) / \mathbf{1 2}(66.66) \\ \text { Diabetes } & \mathbf{1 0}(27.24) & \mathbf{7}(17.5) / \mathbf{3}(16.66) \\ \text { Angina pectoris } & \mathbf{3 2}(55.17) & \mathbf{2 3}(57.5) / \mathbf{9}(50) \\ \text { Myocardial infarction } & \mathbf{2 4}(41.3) & \mathbf{1 8}(45) / \mathbf{6}(33.33) \\ \text { Aortic disease } & \mathbf{1 5}(25.86) & \mathbf{1 1}(27.5) / 4(22.22) \\ \text { Peripheral disease } & \mathbf{5}(8.62) & \mathbf{4}(10) / \mathbf{1}(5.55) \\ \text { Previous CABG } & \mathbf{9}(15.51) & \mathbf{6}(15) / \mathbf{3}(16.66) \\ \text { Previous aortic procedures } & \mathbf{8}(13.79) & \mathbf{2}(5) / 0 \\ \text { Previous peripheral procedures } & \mathbf{2 ( 3 . 4 4 )} & \mathbf{0} \\ \text { Symptoms } & \mathbf{0} & \\ \text { Asymptomatic } & & \\ \text { Symptomatic } & \mathbf{2 8}(48.27) & \\ \text { Transitory ischemic attack } & \mathbf{3 0}(51.73) & \\ \text { Ocular symptoms } & 12(40) & \\ \text { Stroke } & 2(6.66) & \end{array}$

Table 1. Demographic characteristic of the patients and preoperative symptoms

There was no significant difference between ultrasonography and intraoperative findings in the group A. There was significant difference between ultrasonography and intraoperative 
findings of the plaque length on the CCA and ICA among patients of group B. There was significant number of patients with plaque length of $4 \mathrm{~cm}$ and more in the CCA, described in the ultrasonography exam and found intraoperatively. Tables 2 and 3

\begin{tabular}{|c|c|c|c|}
\hline Plaque morphology & $\begin{array}{l}\text { Ultrasonography } \\
\text { Group A } \\
\text { (40 patients) }\end{array}$ & $\begin{array}{l}\text { Intraoperative } \\
\text { findings } \\
\text { Group A } \\
\text { (40 patients) }\end{array}$ & $\mathrm{P}$ \\
\hline $\begin{array}{l}\text { Fibrous plaque/ } \\
\text { with ulceration }\end{array}$ & $\begin{array}{c}7(17.5 \%) / \\
\text { tructio5 }(12.5 \%)\end{array}$ & $\begin{array}{c}5(12.5 \%) / \\
0\end{array}$ & $\mathrm{P}>0.05$ \\
\hline $\begin{array}{l}\text { Lipid plaque/ } \\
\text { with ulceration }\end{array}$ & $\begin{array}{c}5(12.5 \%) / \\
1(2.5 \%)\end{array}$ & $\begin{array}{c}9(22.5 \%) / \\
1(2.5 \%)\end{array}$ & $P>0.05$ \\
\hline $\begin{array}{l}\text { Calcified plaque/ } \\
\text { with ulceration }\end{array}$ & $\begin{array}{l}6(15 \%) / \\
19(48 \%)\end{array}$ & $\begin{array}{c}11(27.5 \%) / \\
14(34.5 \%)\end{array}$ & $\mathrm{P}<0.05$ \\
\hline CCA plaque length $>4 \mathrm{~cm}$ & $19(48 \%)$ & $22(55 \%)$ & $P>0.05$ \\
\hline ICA plaque length $>4 \mathrm{~cm}$ & $12(29.5 \%)$ & $19(48 \%)$ & $\mathrm{P}>0.05$ \\
\hline
\end{tabular}

Table 2. Comparison of ultrasonography and intraoperative findings in the patients of the group A

\begin{tabular}{|c|c|c|c|}
\hline \multirow[t]{2}{*}{ Plaque morphology } & Ultrasonography & $\begin{array}{l}\text { Intraoperative } \\
\text { findings }\end{array}$ & $\mathrm{P}$ \\
\hline & $\begin{array}{c}\text { Group B } \\
\text { (18 patients) }\end{array}$ & $\begin{array}{c}\text { Group B } \\
\text { (18 patients) }\end{array}$ & \\
\hline Fibrous plaque/ & $4(22.2 \%) /$ & $2(11 \%) /$ & $\mathrm{P}>0.05$ \\
\hline with ulceration & $1(5.06)$ & 0 & \\
\hline Lipid plaque/ & $2(11 \%) /$ & $2(11 \%) /$ & $\mathrm{P}>0.05$ \\
\hline with ulceration & 0 & $1(5.06 \%)$ & \\
\hline Calcified plaque/ & $3(16.6 \%) /$ & $6(33.33 \%) /$ & $\mathrm{P}>0.05$ \\
\hline with ulceration & $8(44.44 \%)$ & $7(38.88 \%)$ & \\
\hline CCA plaque length $>4 \mathrm{~cm}$ & $6(33.3 \%)$ & $10(55.55 \%)$ & $P>0.05$ \\
\hline ICA plaque length $>4 \mathrm{~cm}$ & 0 & $3(16.66 \%)$ & $P<0.05$ \\
\hline
\end{tabular}

Table 3. Comparison of ultrasonography and intraoperative findings in the patients of the group B

Intraoperative data were presented in the table 4. Among 58 patients, $22(37.93 \%)$ were operated in conditions of general anesthesia and $26(62.07 \%)$ under cervical plexus block. Mean cross clamping time was measured and presented in Figure 2. There was significantly longer cross clamping time when GR was made after attempted EA. ECA flow restoration was made in 9 (15.6\%) patients with intraoperative decision of the operating surgeon according to the quality of ECA, its' position related to the implanted graft and elapsed time of the procedure. Reimplantation of ECA did not influence on neurological complication rate. 
Early postoperative recovery was uneventful in 36 patients (95\%). Early death was reported in 2 patients $(5 \%)$, due to fatal stroke in the early postoperative time. More one patient had transitory ischemic attack $(2,5 \%)$ and one had minor stroke $(2,5 \%)$. Total rate of neurological complications is $7.5 \%$. Comparison of the neurological complications between the groups found higher rates when EA was unsuccessful and GR performed as a bail out procedure. Permanent cranial nerve injuries were reported in 1 patient $(2.5 \%)$. There was neither early myocardial infarction nor death based on any other cause in this series.

Patients were followed by means of ultrasonography one month after the procedure and yearly thereafter. Mean follow up time was 32 months. Two patients were lost from follow up while 4 patients (10.52\%) died during this period of time. Restenosis of less than $75 \%$ was reported in 2 patients $(5.26 \%)$, restenosis of $75-99 \%$ was found in 1 patient $(2.78 \%)$ successfully treated with carotid stenting (Figure 5). In one patient total occlusion of reconstructed artery was revealed with no neurological symptoms.

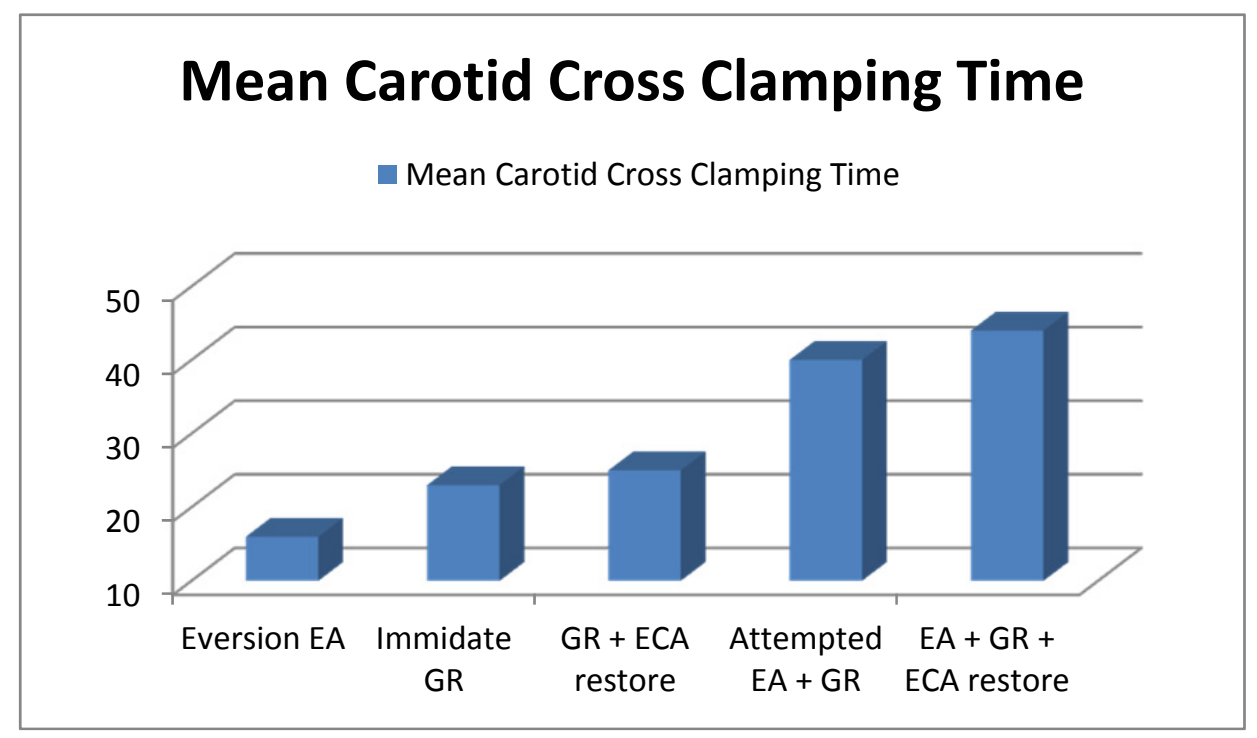

Figure 4. Mean cross clamping time 

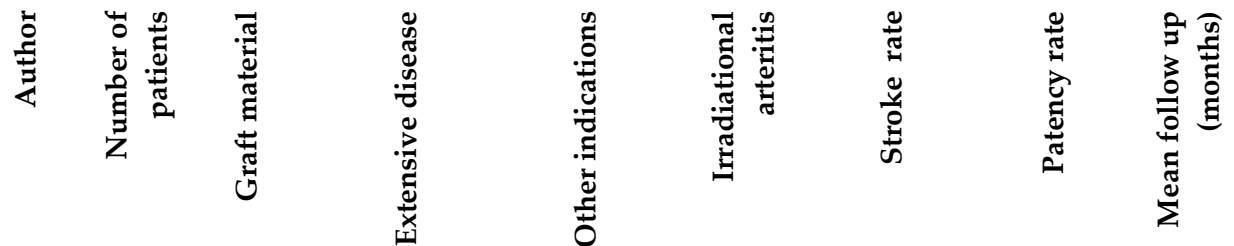

$41 \quad$ PTFE 31

$9(22.5 \%)$

Restenosis 5 (12.19\%)

$4,9 \%$

PTFE $90 \% \quad 50$

$28(68.29 \%)$

Aneurysm

$3(7.31 \%)$

Glomus Tu

$2(4.87 \%)$

Kinking

1 (2.43\%)

Dissection

$1(2.43 \%)$

U్త

110 PTFE

$45(41 \%)$

Restenosis

$18(16.4 \%)$

$7(6.4 \%)$

$0.9 \%$

$95 \%$

22

Kinking

$29(26.4 \%)$

Table 4. Published results since 1979 


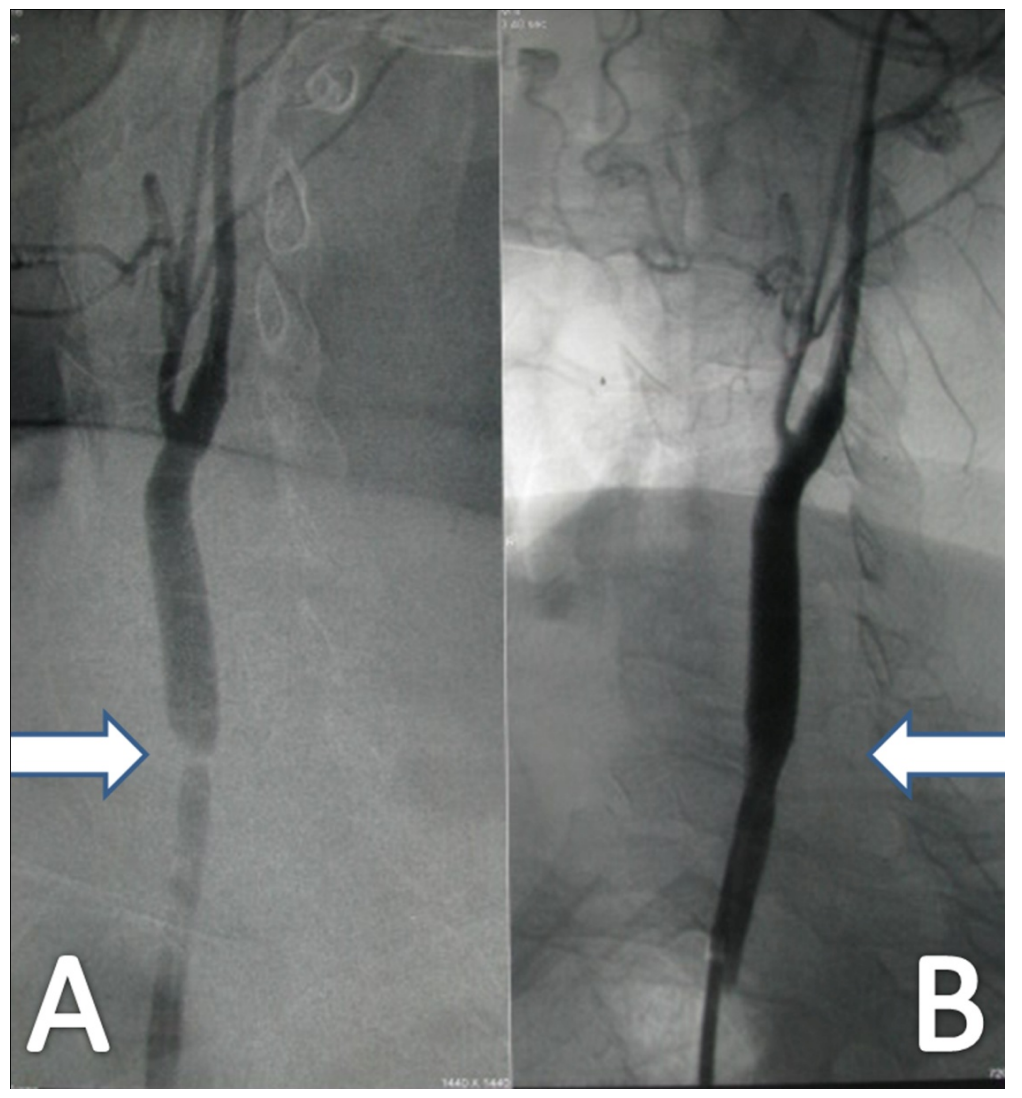

Figure 5. Restenosis at the proximal anastomosis (A) resolved with carotid stenting (B) 


\section{Discussion}

There is no doubt that, over all, endarterectomy is the optimal technique for surgical repair of carotid stenosis. This is the only location where EA is the preferable method nowadays. Choice of EA (conventional or eversion) might cause some discussion between vascular surgeons however the last meta-analysis gave slight advantage to eversion, which was also shown by randomized trial in our institution [27, 28]. Previous Meta analysis showed no difference between the two techniques [27]. The former includes a standard longitudinal carotid arteriotomy with or without patch angioplasty, whereas the second encompasses an oblique transection and eversion of the internal carotid artery and its' reimplantation into the common carotid artery [29, 30,31]. Regarding the carotid artery closure after conventional EA, carotid patch angioplasty is preferable to primary closure [32].

Conventional EA requires usage of graft material that is extending procedure and expose patient to the risk of infection [33]. Eversion EA on the other side does not provide sufficient insight in to the complete endarterectomized surface in the zone at the end of the removed atherosclerotic plaque. Also preparing carotid bifurcation for eversion EA requires its complete deliberation from surrounding tissue which might increase the risk of distal embolizations. Elongated internal carotid artery makes patch suturing more complex while shunt placement in these situations is raising the difficulties. Redundant ICA might simplify eversion EA on the other side. Both of these techniques are related to some advantages and disadvantages including surgeons' familiarity as a specific one. Both of the techniques requires volume of patients in order to achieve good results what might influence the diverse adoption between the teams. According to one multinational registry there is difference in the usage rate of these techniques - in eight European countries EA was performed without patch $(34 \%)$, with patch $(40 \%)$ or with eversion (26\%). Finally, guidelines of the most important and leading societies are leaving the choice between the two techniques to the operating surgeon $[32,34]$. Does it mean that any procedure that removes atherosclerotic plaque from carotid bifurcation and restores flow in a short and long term would be effective in stroke prevention? The similar theory said M.E. DeBakey sixty years ago before his first carotid procedure. DeBakey reasoned that, since endarterectomy and graft replacement in other arteries could be performed, the carotid artery should not be an exception [35].

Carotid stenosis is most frequently localized at the carotid bifurcation leaving proximal and distal segments free from disease providing suitable conditions for endarterectomy. Extension of the atherosclerotic process towards proximally or distally might make endarterectomy cumbersome and risky, while multiple severe atherosclerotic changes at different levels of supra-aortic branches require anatomical or extra-anatomical bypass procedure. Group of patients analyzed in this chapter belongs somewhere between these two patterns of carotid disease - not enough extensive for anatomical bypass through sternotomy while substantially extensive and challenging for eversion EA. 
From technical point of view atherosclerotic process that extends proximally and/or distally aggravates endarterectomy jeopardizing the procedure. Initial problem is carotid clamping. It is necessary to extensively dissect internal and common carotid artery in order to provide safe clamping. Clamping at inadequate location of diseased artery might cause plaque rupture with consequent prone to thrombosis causing perioperative embolizations. Also, clamping at inadequate location could cause incomplete EA causing thrombosis especially at the internal carotid artery location. Preventing incomplete EA in this situation requires additional dissection which is more challenging during clamped and transected carotid artery, it prolongs cross clamping time and might stress inexperienced surgeon provoking other mistakes. Reaching healthy zone is important likewise for shunt users in order to prevent placing a shunt through atherosclerotique plaque inducing distal embolizations. Once reaching the conform clamping zone we are faced with technicaly demanding extensive EA. In case of eversion technique problems are visualization of the end of the plaque zone, adequate flushing of the left surface and removal of small residual intimal particles that are prone to mobilization causing distal embolizations [36]. Extensive dissection of internal carotid artery and its deliberation from surrounding tissue facilitate its eversion. On the contrary, common carotid artery is even more difficult to evert through the whole circumference since the posterior wall is fixed with the external carotid artery. Due to that flexibility of common carotid artery depends on deliberation of external carotid artery from surrounding tissue too. In case of extensive athersoclerosis of common carotid artery and average to minimal process on internal carotid artery it is advisible to transect common carotid artery proximal from its' bifurcation instead of transecting internal carotid artery. This techniqe provides easier EA of common carotid artery in a longer segment [7]. Another technical possibility to deal with extensive atherosclerotic disease in common carotid artery could be semi closed endarterectomy by using Vollmars rings. Finally, for those who preffer conventional technique the very process of EA is quite easier with adequate visualisation of the end of the plaque zone, however, finally the Achille heel of this method is long patch anastomosis that is technicaly demanding and more prone to neointimal hyperplasia or false aneurysm. Anastomotic bleeding on the long patch is another technical difficutly especialy when using intraluminal shunt. Upon removing the shunt, brain perfusion is reduced until complete haemostasis is provided making declamping safe. Loosing time on resolving anastomotic bleeding could cause ishemic brain injury. Overcoming all these technical difficulties does not guarantee sucess since long endarterectomy is leaving long thrombogenic surface prone to in situ thrombosis or distal embolizations jeopardizing the results of the procedure regardless to excellent surgical technique.

All these difficulties were encountered in peripheral vascular surgery inducing usage of different conduits in the reconstructive bypass procedures; similar was done in carotid surgery although less frequently. Bypass in this location could have a good long term potential since it is connecting two healthy arteries with high blood flow and loaded recipient vascular bed, like cerebral, which is inducing low resistance. Still low number of publications is describing this technique in the last 30 years with usage of different conduits. 
Consequently in the two most respected guidelines for treatment of carotid stenosis this option is not mentioned. However a short review of the published data related to this technique is given below with some technical remarks from the authors of this chapter.

In 1979 M.E.Debakey published his experience in usage of synthetic graft for repair of carotid artery injury [37]. In the same year Cormier and all started to use this type of reconstruction reporting their experience eight years later [38]. Among 62 treated patients $54(87 \%)$ were treated due to extensive atherosclerotic disease, with $5 \%$ stroke rate and $97 \%$ patency in the 23 months long term follow up. Later, different types of reconstruction were reported using various conduits. Camiade and all used PTFE graft suture with side to end proximally and end to side anastomosis distaly [39]. This technique minimizes dissection of carotid bifurcation and preserves patency of external carotid artery. Authors performed this procedure in 110 patients, indicated it in case of extensive atherosclerotic disease in $45(41 \%)$, while using it also for reconstruction in case od restenosis $(16.4 \%)$ or kinking (26.4\%). There were some other authors reporting usage PTFE graft with similar patency of $95-97 \%$ in the long term $[40,41]$. The only author that used Dacron graft was Valdeniz with results comparable to those published with PTFE [42]. Autologous saphenous vein was also reported by various authors, some of them complaining on high restenosis rate. French authors are reporting good early and long term results [43, 44, 45]. In 212 patients treated due to extensive atherosclerotic disease $(76 \%)$, restenosis $(5.6 \%)$, kinking $(8.49 \%)$ and aneurysm $(4.24 \%)$ they reported $5 \%$ stroke rate and $96 \%$ patency after average 104 months of follow up. On the other side according to the Leicester group saphenous vein is prone to early restenosis in this position even though they performed different anastomotic techniques [46]. According to the diameter of the vein graft and common carotid artery they located anastomosis at the lateral wall of common carotid artery, at the origin of internal carotid artery or at the origin of external carotid artery after its' exclusion. After average follow up of 60 months patency rate was $83 \%$ with significant incidence of restenosis. According to opinion of the authors of this chapter vein graft could be perfect for this procedure, however one might expect misfit of the calibers. Additionally harvesting this graft could be time consuming if so if the graft replacement is performed as a bailout procedure it might prolong cross clamping time and procedure. It is not convenient for carotid procedures performed in cervical plexus block and finally saphenous vein is important conduit for coronary revascularization and should be preserved for that occasion as well. This conduit could be unavailable in patients with varicose syndrome and previous coronary revascularization. Latest publication is from W. Moore reporting 17 years of experience using both synthetic and saphenous vein grafts with satisfying results [47]. 31 PTFE and 10 saphenous grafts were followed for 50 months with patency of $90 \%$ and $80 \%$, respectively. Carotid graft replacement is already proved procedure in some other pathology like carotid artery aneurysm and restenosis [48, 49].

Summarized published data show 613 carotid procedures where bifurcation was reconstructed with GR. In all these publications the most frequent indication for graft usage was extensive atherosclerotic disease with involvement of common or distal internal carotid 
artery - 328 procedures (53.5\%). Other indications were carotid recurrent stenosis, technical failure of attempted EA, stenosis after radiation therapy, carotid aneurysm and carotid stenosis associated with kinking. Among 613 carotid stenosis treated with GR, 290 (47,3\%) procedures were performed with PTFE graft, 272 (44,37\%) with saphenous graft and 51 $(8,31 \%)$ with Dacron. Extensive and detailed information regarding published data are shown in the Table 4.

\section{Conclusion}

When it comes to carotid stenosis, EA is the method of choice in majority of patients. Small subgroup of patients had extensive carotid atherosclerotic disease that involves common or internal carotid artery in a segment longer than $4 \mathrm{~cm}$. In these situations modification of surgical procedure is necessary since EA might be jeopardized. Optimal scenario would be to assess extension of atherosclerotic process preoperatively through ultrasonography or MSCT angiography or intraoperatively during dissection of carotid arteries. In case of extensive atherosclerotic process, decision to perform carotid graft replacement without any attempt of EA could simplify procedure, shorten cross clamping time and avoid technical and thromboembolic complications. Conduit choice is the matter of operating surgeon. Upon clamping and resecting diseased segment, suturing distal anastomosis first is recommendable in order to provide easier manipulation and better visualization of anastomotic line. Next step is suturing the proximal anastomosis then flushing and finally carotid declamping. Reimplantation of external carotid artery is not mandatory and the decision should be made as the preference of the surgeon. Efforts to perform EA even in case of extensive disease could be effective especially in experienced hands, however in case of any doubts in wall quality or end of the plaque zone, graft replacement should be performed before flow restoration in order to prevent fatal complications that this procedure carries.

There is not enough evidence to provide any accurate criteria for usage of carotid graft replacement instead of endarterectomy. This chapter showed results, experience and technical details of a single high volume center and presented not so reach published material. Decision to perform graft replacement should be made individually according to anatomy and morphology of carotid disease. Wide surgical experience affords expertise and improves individual decision making.

\section{Author details}

Igor Koncar, Nikola Ilic, Marko Dragas, Miroslav Markovic, Dusan Kostic and Lazar Davidovic

Clinic for Vascular and Endovascular Surgery, Serbian Clinical Centre, Serbia

Medical Faculty, University of Belgrade, Serbia

Igor Banzic

Clinic for Vascular and Endovascular Surgery, Serbian Clinical Centre, Serbia 


\section{Acknowledgments}

Authors would like to thank to Katarina Kaplarski for providing illustrations of the procedure.

Presented study is a part of a scientific research project (Grant OI175008) supported by the Ministry of Education and Science of the Republic of Serbia.

\section{References}

[1] Chiari H: Ueber Verhalten Teilungswinkels der Carotis communis bei der Endarteritis chronica deformans. Verh Dtsch Pathol Ges 1905; 9:326-330.

[2] Moniz E, Lima A, de Lacerda R: Hemiplegies par thrombose de la carotide interne.Presse Med 1937; 45:977-980.

[3] Carrea R, Molins M, Murphy G: Surgical treatment of spontaneous thrombosis of the internal carotid artery in the neck: carotid-carotideal anastomosis.Report of a case.Acta Neurol Latinoamer 1955; 1:71-78.

[4] Eastcott HHG, Pickering GW, Rob CG: Reconstruction of internal carotid artery in a patient with intermittent attacks of hemiplegia. Lancet 1954; 2:994-996.

[5] Debakey ME: Successful carotid endarterectomy for cerebrovascular insufficiency: nineteen year follow-up. JAMA 1975; 233:1083-1085.

[6] Rowe WF. An early successful carotid endarterectomy, not previously reported. Paper presented at the Annual Meeting of the Southern California Vascular Surgical Society, September 18th, 1993, Coronado, CA

[7] Cooley DA, Al-Naaman YD, Carton CA: Surgical treatment of arteriosclerotic occlusion of the common carotid artery.J Neurosurg 1956; 13:500-506

[8] North American Symptomatic Carotid Endarterectomy Trial Collaborators: Beneficial effect of carotid endarterectomy in symptomatic patients with high-grade carotid stenosis. N Engl J Med 1991; 325:445-453.

[9] North American Symptomatic Carotid Endarterectomy Trial Collaborators: Benefit of carotid endarterectomy in patients with symptomatic moderate or severe stenosis. $\mathrm{N}$ Engl J Med 1998; 339:1415-1425.

[10] European Carotid Surgery Trialists' Collaborative Group: MRC European Carotid Surgery Trial: interim results for patients with severe $(70-99 \%)$ or mild $(0-29 \%)$ carotid stenosis. Lancet 1991; 337:1235-1243.

[11] Executive Committee of the Asymptomatic Carotid Atherosclerosis Study: Endarterectomy for asymptomatic carotid artery stenosis. JAMA 1995; 273:1421-1428.

[12] ACST Collaborators Group: The International Asymptomatic Carotid Surgery Trial (ACST). Lancet 2004; 363:1491-1502.

[13] Alison Halliday, Michael Harrison, Elizabeth Hayter, Xiangling Kong, Averil Mansfield, Joanne Marro, Hongchao Pan, Richard Peto, John Potter, Kazem Rahimi, Angela Rau, Stephen Robertson, Jonathan Streifler, Dafydd Thomas, on behalf of the Asymptomatic Carotid Surgery Trial (ACST) Collaborative Group*10-year stroke 
prevention after successful carotid endarterectomy for asymptomatic stenosis (ACST-1): a multicentre randomised trial. Lancet 2010; 376: 1074-84

[14] LeFevre H: Sur un cas de plaie du bulbe carotidien per balle, traitee par la ligature de la carotid primitive, et l'anastomose bout et bout de la carotid externe avec la carotid interne. Bull Mem Soc Chir 1918; 44:923-928.

[15] Dimitza A: Aneurysms of the carotid arteries. Report of 2 cases. Angiology 1956; 7:218227.

[16] Beall Jr AC, Crawford ES, Cooley DA, DeBakey ME: Extracranial aneurysms of the carotid artery. Report of seven cases. Postgrad Med 1962; 32:93-102.

[17] Vaughan GD, Mattox KL, Feliciano DV, Beall AC Jr, DeBakey ME. Surgical experience with expanded polytetrafluoroethylene (ePTFE) as a replacement graft for traumatized vessels. J Trauma 1979;19:403-98.

[18] Denman FR, Ehni G, Duty WS. Insidious thrombotic oclusion of cervical carotid arteries, treated by arterial graft; a case report. Surgery 1955, 38 (3): 569-77.

[19] Doyle EJ, Javid H, Lin PM. Partial internal carotid artery occlusion treated by primary resection and vein graft; report of a case. Jneurosurg 1956, 13 (6): 650-5.

[20] Dos Santos JC: Sur la desobstion des thromboses arterielles anciennes. Mem Acad Chir 1947; 73:409.

[21] Wylie EJ, Kerr E, Davies O: Experimental and clinical experiences with the use of fascia lata applied as a graft about major arteries after thromboendarterectomy and aneurysmorrhaphy. Surg Gynecol Obstet 1951; 93:257.

[22] Van der Akker PJ, van Schilfaarde R: Long-term results of prosthetic and non-prosthetic reconstruction for obstructive aorto-iliac disease. Eur J Vasc Surg 1992; 6:53.

[23] Stoney RJ, Reilly LM: Endarterectomy for aortoiliac occlusive disease. In: Ernst CB, Stanley JC, ed. Current Therapy in Vascular Therapy, Philadelphia: BC Decker; 1987:157.

[24] Inahara T: Evaluation of endarterectomy for aortoiliac and aortoilio-femoral occlusive disease. Arch Surg 1975; 110:1458.

[25] Brewster DC, Darling RC: Optimal methods of aortoiliac reconstruction. Surgery 1978; 84:739.

[26] Darling RC, Paty PS, Shah DM, Chang BB, Leather RP. Eversion endarterectomy of the internal carotid artery: technique and results in 449 procedures. Surgery. 1996;120(4):635-639.

[27] Cao PG, de Rango P, Zannetti S, Giordano G, Ricci S, Celani MG. Eversion versus conventional carotid endarterectomy for preventing stroke. Cochrane Database Syst Rev 2001;(1). CD001921

[28] Markovic DM, Davidovic LB, Cvetkovic DD, Maksimovic ZV,Markovic DZ, Jadranin DB. Single-center prospective, randomized analysis of conventional and eversion carotid endarterectomy. J Cardiovasc Surg (Torino) 2008;49(5):619-25.

[29] Ballotta E, Da Giau G, Saladini M, Abbruzzese E, Renon L, Toniato A. Carotid endarterectomy with patch closure versus carotid eversion endarterectomy and reimplantation: a prospective randomized study. Surgery 1999;125(3):271-9 
[30] Kieny R, Hirsch D, Seiller C, Thiranos JC, Petit H. Does carotid eversion endarterectomy and reimplantation reduce the risk of restenosis? Ann Vasc Surg 1993;7(5):407-13

[31] Raithel D. Carotid eversion endarterectomy: a better technique than the standard operation? Cardiovasc Surg 1997;5(5):471-2.

[32] Liapis CD, Bell PR, Mikhailidis D, Sivenius J, Nicolaides A, Fernandes e Fernandes J, et al. ESVS guidelines. Invasive treatment for carotid stenosis: indications, techniques. Eur J Vasc Endovasc Surg 2009;37(4 Suppl):1-19

[33] C.D. Mann, M. McCarthy, A. Nasim, M. Bown, M. Dennis, R. Sayers, N. London, A.R. Naylor. Management and Outcome of Prosthetic Patch Infection after Carotid Endarterectomy: A Single-centre Series and Systematic Review of the Literature Eur J Vasc Endovasc Surg 44 (2012) 20-26

[34] C. Liapis, W.C. Mackey, B. Perler, P. Cao Comparison of SVS and ESVS Carotid Disease Management Guidelines Eur J Vasc Endovasc Surg (2009) 38, 243-245

[35] A History of Vascular Surgery SECOND EDITION, Steven G. Friedman, Blackwell Publishing, Inc, 2005

[36] Berguer R, Kieffer E. (1992): Surgery of the Arteries to the Head, Springer-Verlag, New York, Berlin, Heidelberg, 74 -206.

[37] Vaughan GD, Mattox KL, Feliciano DV, Beall AC Jr, DeBakey ME.Surgical experience with expanded polytetrafluoroethylene (ePTFE) as a replacement graft for traumatized vessels. J Trauma 1979;19:403-98.

[38] Cormier F, Laurian C, Gigou F, Fichelle JM, Bokobza B. Polytetrafluoroethylene bypass for revascularization of the atherosclerotic internal carotid artery: late results Annals Of Vascular Surgery , 1987 Dec;1(5):564-71

[39] Christophe Camiade, Amer Maher, Jean-Baptiste Ricco, Jerome Roumy, Guillaume Febrer, Christophe Marchand, Jean-Philippe Neau. Carotid bypass with polytetrafluoroethylene grafts: A study of 110 consecutive patients. J Vasc Surg 2003;38:1031-8.

[40] Sise MJ, Ivy ME, Malanche R, Ranbarger KR. Polytetrafluoroethylene interposition grafts for carotid reconstruction. J Vasc Surg 1992;16:601-8.

[41] Becquemin JP, Cavillon A, Brunel M, Desgranges P, Melliere D. Polytetrafluorethylene grafts for carotid repair. Cardiovasc Surg 1996;4:740-5.

[42] Henry C. Veldeniz, Rhea Kinser, George Neil Yates. Carotid graft replacement: A durable option J Vasc Surg 2005;42:220-6.

[43] Branchereau A, Pietri P, Magnan PE, Rosset E. Saphenous vein bypass: an alternative to internal carotid reconstruction. Eur J Vasc Endovasc Surg 1996;12:26-30.

[44] Voirin L, Magne JL, Farah I, Sessa C, Chichignoud B, Guidicelli H. Carotid revascularizations by venous grafting: long-term results. Chirurgie (Paris) 1997;122:34650.

[45] Fabiani JN, Julia P, Chemla E, Birnbaum PL, Chardigny C, D'Attellis N, et al. Is the incidence of recurrent carotid artery stenosis influenced by the choice of the surgical technique: carotid endarterectomy versus saphenous vein bypass. J Vasc Surg 1994;20:821-5. 
[46] C. Lauder, A. Kelly, M. M. Thompson, N. J. M. London, P. R. F. Bell, A. R. Naylor. Early and late outcome after carotid artery bypass grafting with saphenous vein J Vasc Surg 2003;38:1025-30.

[47] Amir H Dorafshar, Todd D Reil, Samuel S Ahn, William J Quinones-Baldrich, Wesley S Moore Interposition Grafts for Difficult Carotid Artery Reconstruction: A 17-Year Experience Ann Vasc Surg. 2007 Dec 11; : 18082917 (P,S,E,B,D).

[48] Radak D, Davidovic L, Tanaskovic S, Koncar I, Babic S, Kostic D, Ilijevski N. Surgical treatment of carotid restenosis after eversion endarterectomy-serbian bicentric prospective study. Ann Vasc Surg. 2012 Aug;26(6):783-9.

[49] Radak D, Davidović L, Vukobratov V, Ilijevski N, Kostić D, Maksimović Z, Vucurević G, Cvetkovic S, Avramov S. Carotid artery aneurysms: Serbian Multicentric Study. Ann Vasc Surg. 2007 Jan;21(1):23-9. 